Marcia Hespanhol Bernardo

Andréia De Conto Garbin²

\title{
A atenção à saúde mental relacionada ao trabalho no SUS: desafios e possibilidades
}

\author{
Work-related mental health care in the Brazilian national health \\ system: challenges and possibilities
}

\section{Resumo}

Este ensaio contextualiza a estruturação das áreas de saúde mental e saúde do trabalhador no Sistema Único de Saúde (SUS) com o intuito de discutir as possibilidades de atuação intrassetorial com relação à saúde mental relacionada ao trabalho. Inicia mostrando a complexidade das áreas programáticas de Saúde Mental e de Saúde do Trabalhador e indica que os maiores desafios a serem superados no contexto atual são a integração entre elas e a superação de uma "cultura" ainda presente na sociedade, segundo a qual o trabalho, quase sempre, tem uma conotação positiva e o sofrimento/adoecimento psíquico é visto como um sinal de fraqueza pessoal. A partir do relato de experiências, também aborda as possibilidades e os desafios na atenção à saúde mental relacionada ao trabalho nos diferentes níveis de atenção do SUS. Focaliza, mais especificamente, as ações possíveis na rede básica, o potencial da integração entre serviços especializados de saúde mental e de saúde do trabalhador para o estabelecimento de nexo causal, a importância dos eventos sentinelas e a necessidade da notificação dos agravos à saúde mental relacionados ao trabalho.

Palavras-chave: saúde mental e trabalho; saúde mental; saúde do trabalhador; SUS; agravos à saúde mental.

\begin{abstract}
This essay sets the context of mental health and worker's health care in Brazilian National Health System and discusses possible actions regarding work-related mental health. It begins by presenting the complexity of both Mental Health and Worker's Health programmatic areas and points out two main challenges yet to overcome in the current context: integrating both health care systems and rejecting the current "culture", in which work receives a positive connotation, while psychic suffering/illness is seen as a personal weakness. Based on reports of experience, the article also brings up the possibilities and challenges of work-related mental health care in different levels of care offered by Brazilian National Health System. It focuses more specifically on possible actions to be taken at primary care level as well as at the potential integration between mental health specialized services and worker's health, aiming at establishing causal nexus. It also demonstrates the importance of sentinel surveillance and the need of compulsory notification of work-related mental health disorders.
\end{abstract}

Keywords: mental health and work; mental health; occupational health; health system; mental health disorders. 


\section{Introdução}

Este ensaio tem por objetivo discutir as possibilidades de ações do Sistema Único de Saúde (SUS) nos seus diversos níveis com relação à atenção à saúde mental relacionada ao trabalho. Entendemos que os maiores desafios a serem superados no contexto atual sejam a integração entre as áreas programáticas de Saúde Mental e de Saúde do Trabalhador e a superação de uma cultura ainda presente na sociedade, segundo a qual o trabalho, quase sempre, tem uma conotação positiva e o sofrimento/adoecimento psíquico é visto como um sinal de fraqueza pessoal.

\section{Saúde Mental e Saúde do Trabalhador: uma integração possível?}

Esses dois campos têm em comum a concepção de saúde como fenômeno social e de interesse público. Pode-se também dizer que ambos ganharam espaço relevante enquanto áreas programáticas do SUS devido à mobilização de movimentos populares e de profissionais de saúde, tais como o Movimento de Reforma Sanitária (CAMPOS, 2007), o Movimento dos Trabalhadores da Saúde Mental (AMARANTE, 1995; SCARCELLI; ALENCAR, 2009) e o Movimento Sindical (LACAZ, 1996). Scarcelli e Alencar (2009) lembram-nos de que tais movimentos "começaram a se organizar ainda durante o período da ditadura militar e se intensificaram durante o período de 'abertura política”' (p. 3). E, de acordo com Campos (2007), foram os integrantes do Movimento Sanitário que elaboraram “a política, diretrizes e, até mesmo, o modelo operacional do SUS” (p. 1868).

No entanto, mesmo que os Movimentos de Saúde Mental e de Saúde do Trabalhador tenham tido parte de suas origens relacionadas ao Movimento Sanitário e que as ações propostas desde então estejam fundamentadas nos princípios básicos que regem o SUS, não se pode dizer que o olhar para as questões envolvidas nessas áreas tenha sido incorporado de forma plena em todos os níveis de atenção desse sistema. E devemos lembrar que o SUS já completou vinte anos de existência.

Se é assim, não é difícil deduzir que existe uma dificuldade ainda maior para o enfrentamento de questões que se situam na fronteira entre esses dois campos e que, portanto, demandam a integração entre eles. Falamos aqui, especificamente, de saúde mental relacionada ao trabalho.

Partindo desse pressuposto, no texto que segue, contextualizamos as áreas programáticas de Saúde Mental e de Saúde do Trabalhador no SUS. Retomando alguns aspectos históricos, discutimos as dificuldades ainda enfrentadas por cada uma delas no contexto atual e os possíveis obstáculos para sua integração. Essa contextualização possibilita uma base para a discussão de possíveis e necessárias ações do SUS para a atenção aos problemas de saúde mental relacionados ao trabalho, que apresentamos em seguida, tomando como referência a experiência das autoras. ${ }^{3}$

\section{A área de Saúde Mental no SUS}

Pode-se dizer que, até a década de 1980, a atenção à saúde mental no âmbito da saúde pública no Brasil acompanhava o modelo que, de acordo com Foucault (1972), predominou durante mais de duzentos anos em quase todo o mundo ocidental: o asilo. Tal modelo consistia, quase que exclusivamente, na segregação de todos aqueles que apresentavam "diferenças, desvios e divergências sociais e culturais" (AMARANTE, 1995, p. 292), incluindo os chamados "loucos", que eram internados nos manicômios. No Brasil, a aplicação prática desse modelo se dava por meio de convênios do poder público com manicômios, nos quais o "tratamento" consistia, basicamente, na aplicação massiva de medicamentos e utilização de outros métodos para trazer o paciente à "normalidade”, como o eletrochoque. Problemas de saúde mental que não se configurassem como uma forma desviante dos padrões sociais tinham pouca ou nenhuma possibilidade de serem objeto de atenção no âmbito da saúde pública.

A maior parte dos manicômios se configurava como verdadeiros depósitos, nos quais os pacientes não tinham condições mínimas de dignidade humana. Os maus-tratos eram comuns, como se observou em muitas incursões conjuntas do Conselho Federal de Psicologia e do Conselho Federal da Ordem dos Advogados do Brasil em atividades de inspeção nesses locais, realizadas na última década (CONSELHO FEDERAL DE PSICOLOGIA, 2001, 2004, 2006, 2008a).

Considerando esse contexto, as preocupações do Movimento dos Trabalhadores de Saúde Mental (MTSM) foram além daquelas manifestadas pelo Movimento Sanitário. Não se tratava apenas da reformulação dos sistemas de saúde como parte integrante do processo de redemocratização do país, com ações de atenção, assistência, prevenção, proteção e promoção de saúde. Na Saúde Mental, o foco também estava no papel normalizador das instituições e na desinstitucionalização. Nesse sentido, Amarante (1995) afirma que,

[...] procurando entender a função social da psiquiatria e suas instituições para além do seu papel explicitamente médico-terapêutico, o MTSM constrói um pensamento crítico no campo da saúde mental que permite visualizar uma possibilidade de inversão desse modelo a partir do conceito de desinstitucionalização (p. 492).

\footnotetext{
${ }^{3}$ As autoras deste artigo têm, cada uma, mais de uma década de atuação no SUS com variadas inserções (serviços relacionados à Saúde Mental, Saúde do Trabalhador e gestão em nível central e local) e em diferentes municípios (São Paulo, Campinas, Diadema e São Bernardo do Campo).
} 
Sendo assim, é possível compreender porque as políticas públicas decorrentes das proposições desse movimento tenham focalizado, primordialmente, a atenção aos casos graves - especialmente as psicoses - a partir do estabelecimento de uma rede substitutiva ao modelo asilar.

Vale dizer que, juntamente com a substituição dos manicômios, também era essencial substituir a cultura manicomial predominante na sociedade (AMARANTE, 2000). Desse modo, além da constituição de uma rede de serviços, era necessário conquistar os diversos setores sociais para a "causa" da reforma psiquiátrica, incluindo os profissionais de saúde cuja formação, em grande parte, tinha (e, talvez, possa-se dizer que ainda tenha $)^{4}$ um cunho essencialmente manicomial.

As primeiras vitórias efetivas desse movimento no âmbito nacional se deram no início dos anos 1990, quando, após a implantação de serviços de cunho antimanicomial em alguns municípios, como Santos e São Paulo, o Ministério da Saúde publicou as portarias (BRASIL, 1991, 1992) que possibilitaram o financiamento de outros serviços de saúde mental que não apenas o leito psiquiátrico. No que diz respeito ao trabalho, vale lembrar que a Lei n⿳o 9.867/99, que criou e definiu o funcionamento de cooperativas sociais, também foi um marco para a reforma psiquiátrica brasileira na medida em que possibilitou o desenvolvimento de programas de trabalho assistido "com a finalidade de inserir as pessoas em desvantagem no mercado econômico" (BRASIL, 1999).

Mas foi sobretudo com a publicação, em 2001, da Lei Federal no 10.216 (BRASIL, 2001a) que passou a haver um investimento público massivo para a implantação e implementação de dispositivos assistenciais específicos - principalmente Centros de Atenção Psicossocial (CAPS) - visando à extinção progressiva dos manicômios em todo o território nacional e privilegiando a autonomia e a reinserção social daqueles que vivem com sofrimento mental.

No entanto, se tais medidas possibilitaram a criação de uma rede de saúde mental substitutiva aos manicômios, houve relativamente pouco investimento em estratégias para incluir, nessa rede, outros serviços do SUS não específicos dessa área. Assim, observa-se que, de um modo geral, os CAPS ainda centralizam a atenção a uma ampla gama de casos de sofrimento psíquico e de transtorno mental que poderiam ser atendidos nos diferentes níveis de atenção e de cuidado, inclusive com investimento em soluções regionais mediante compromissos e pactuações.
Além disso, as ações de prevenção e promoção de saúde também parecem longe de ser os aspectos mais relevantes da agenda da saúde mental no SUS na atualidade. E, ainda, conforme afirma Passos (2009), a própria área de saúde mental também se mostra "um tanto quanto apartada dos problemas mais gerais de saúde coletiva e da rede de atenção básica”.

Nesse sentido, Scarcelli e Alencar (2009) ponderam que:

se, por um lado, foram muitos os avanços nos últimos anos no que se refere à reforma psiquiátrica brasileira, por outro lado, a questão da desconstrução da cultura manicomial foi suplantada por aquelas centradas, muitas vezes, nos aspectos fundamentalmente assistenciais (p. 6).

E, assim:

parte das preocupações a ações propostas pelos movimentos que se organizam no final do regime militar e se ampliam no processo de redemocratização do país ficaram latentes nos anos que se seguiram (p. 6).

A vivência das autoras deste artigo na área de saúde em diferentes municípios indica a hipótese de uma dupla exclusão. Por um lado, parece que, de fato, as unidades de atenção especializada em Saúde Mental, como os CAPS, estão mais focadas na assistência e distantes das questões gerais de saúde coletiva. Mas, por outro, não parece haver ações efetivas de grande parte dos gestores de saúde, seja no nível municipal ou local, para que a atenção à saúde mental seja amplamente assimilada por outros serviços e profissionais que não sejam aqueles diretamente vinculados à área. Desse modo, ainda que não se possa negar a existência de experiências que obtiveram êxito nessa integração, não é possível afirmar que exista uma organicidade na atenção à saúde mental em serviços de saúde não especializados, sobretudo na atenção básica.

Avaliamos que existem dois fatores que, apesar de estarem vinculados a concepções opostas de atenção à saúde, dificultam igualmente a superação desse distanciamento.

De um lado está a atual Estratégia de Saúde da Família (ESF). Sem dúvida, trata-se de uma proposta muito importante, que se fundamenta na atenção integral e na territorialização, ${ }^{5}$ as quais, devemos ressaltar, também são conceitos-chave para a atenção psicossocial, que está na base da política de Saúde Mental. Mas sua estruturação com base em equipes formadas apenas por médicos e profissionais de enfermagem "generalistas" parece dificultar o olhar para situações e problemas de saúde que, historicamente, ficaram apartados da atenção básica. Entre eles, incluem-se não apenas a Saúde Mental, mas

\footnotetext{
${ }^{4}$ A esse respeito, é interessante ler o relato de Passos (2009), sobre o curso de Psicologia da Universidade Federal de Minas Gerais.

${ }^{5}$ Uma compreensão mais ampla da territorialização deveria ir além da área de abrangência do atendimento das equipes de Saúde da Família ou da Unidade Básica de Saúde. De acordo com Ceccim (2005, p. 176), "processo de territorialização não se restringe à dimensão técnico-científica do diagnóstico e da terapêutica ou do trabalho em saúde, mas se estende à orientação das práticas, à construção de um estar no campo de saberes e de práticas da saúde que envolve desterritorializar saberes hegemônicos e práticas vigentes".
} 
também a Saúde do Trabalhador e as demais áreas que fazem parte da Vigilância em Saúde (saúde ambiental, sanitária, epidemiológica e controle das zoonoses).

No outro extremo está a formação dos profissionais de saúde mental - especialmente psiquiatras e psicólogos - que ainda é fortemente influenciada por vertentes individualizantes. A formação médica em psiquiatria, de um modo geral, preconiza terapêuticas medicamentosas como a solução para a maior parte dos problemas de saúde mental. Já no campo da psicologia, as teorias predominantes - entre as quais, a psicanálise se destaca - enfatizam os aspectos individuais e familiares como as principais causas do adoecimento e do sofrimento psíquico, indicando a psicoterapia como a forma primordial de tratamento. Em ambas as concepções, o foco está em ações assistenciais e não na prevenção do adoecimento ou na promoção de saúde. Assim, a atenção em saúde mental se daria apenas por meio da atenção do "especialista" ao "indivíduo doente", sendo deixados de lado aspectos sociais que compõem a complexa trama de fatores que podem desencadear o sofrimento e o adoecimento mental, entre os quais está o trabalho.

Tais fatos parecem ter colaborado para que a atenção à saúde mental tenha ficado concentrada em unidades especializadas, sobretudo nos CAPS, e mantido uma tendência fortemente assistencial mesmo após a reforma psiquiátrica, conforme afirmam Scarcelli e Alencar (2009).

Mais recentemente, foram criados os Núcleos de Apoio à Saúde da Família (NASFs), que são estruturas compostas por equipes multiprofissionais, que devem atuar como referência para um número determinado de equipes de saúde da família no sentido de realizar discussão de casos, atendimento compartilhado e, eventualmente, intervenções específicas com usuários e famílias encaminhados (BRASIL, 2008). A criação desse tipo de serviço é, sem dúvida, um avanço no sentido de aproximar a área especializada da atenção básica. Mas, para funcionar adequadamente, exige o exercício permanente da formação e da pactuação de novas regras para integração. É interessante destacar que, em um documento produzido pelo Conselho Federal de Psicologia (2009), no qual são relatadas as experiências de diversos psicólogos que atuam em NASFs, são apresentadas diversas dificuldades, entre as quais:

a falta de preparo básico em discussões relacionadas à subjetividade e uma grande sensação de desamparo frente às demandas extremamente complexas no cotidiano do serviço. (p. 107)

Observa-se, assim, que, na atualidade, ainda existem muitos obstáculos a serem superados no sentido de incorporar, na prática de atenção à saúde mental no SUS, os ideais preconizados pelo movimento da reforma psiquiátrica. Mas também devemos lembrar que existem municípios onde a atenção à saúde men- tal teve grandes avanços, com mudanças significativas na direção de uma política antimanicomial no seu sentido pleno.

\section{A área de Saúde do Trabalhador no SUS}

Deve ser ressaltado que, desde a década de 1930 até a estruturação do SUS, a assistência à saúde da população trabalhadora não dizia respeito à saúde pública e era atribuição das empresas e da Previdência Social (LACAZ, 1996). É somente a partir da aliança dos sindicatos com profissionais de saúde alinhados às propostas do movimento sanitário que a Saúde do Trabalhador passa a ser objeto de atenção. Conforme apontado em documento sobre esse tema elaborado pelo Centro de Referência Técnica em Psicologia e Políticas Públicas (CREPOP) do Conselho Federal de Psicologia:

Longe de ser um termo apenas descritivo e sinônimo da Saúde Ocupacional, Saúde do Trabalhador refere-se a um campo de saberes e práticas com claros compromissos teóricos, éticos e políticos, e insere-se como uma política pública em saúde que demanda articulações intersetoriais (Saúde, Previdência Social, Educação, Trabalho e Emprego, Meio Ambiente, dentre outras). A amplitude do campo teórico e prático da Saúde do Trabalhador exige a inter-relação de diversos saberes e a apreensão de múltiplos conceitos. (CONSELHO FEDERAL DE PSICOLOGIA, 2008b, p. 17)

Trata-se de um modelo fundamentado nas proposições da área Saúde Coletiva e da Medicina Social Latino-americana (LACAZ, 1996; LAURELL, 1991; MINAYO-GOMEZ; THEDIM-COSTA, 1997) e influenciado também pelas proposições de organismos internacionais, como a Organização Internacional do Trabalho (OIT) e a Organização Panamericana de Saúde (OPAS) (TAMBELLINI, 1984; LACAZ, 1996; SATO; LACAZ; BERNARDO, 2006).

Nessa concepção, a saúde pública deveria partir do reconhecimento de que a relação capital-trabalho se estabelece de forma desigual e suas ações deveriam ter por objetivo proteger o lado mais frágil desse binômio, o trabalhador. Ao incluir os aspectos sociais, também se buscava superar o olhar tradicional da Medicina do Trabalho, que tende a focalizar a relação saúde-trabalho unicamente como uma relação de causa-efeito entre um agente do ambiente e um indivíduo trabalhador.

A partir de meados dos anos 1980, surgiram, então, alguns Programas de Saúde do Trabalhador (PSTs) cujas equipes foram, em grande parte, formadas por profissionais "militantes" do Movimento Sanitário (LACAZ, 1996; COSTA; et al., 1989). A proposta inicial era a de que essas unidades funcionassem como polos facilitadores para que a rede de saúde atentasse para as especificidades do trabalho no processo saúde/doença. Além da necessidade de um olhar crítico para a relação entre saúde e trabalho, também era essencial que os profissionais e os gestores de saúde aprendessem e se dispusessem a manejar diversas situações, que, em geral, são fontes de intensos conflitos. 
Tais experiências, apesar de isoladas, foram fundamentais para a inclusão dessa área programática no capítulo de Saúde da Constituição Federal de 1988 e na lei que regulamenta o SUS. Os dispositivos constitucionais definem a Saúde do Trabalhador como um conjunto de ações de atenção, promoção, prevenção e proteção à saúde que visa à recuperação e à reabilitação da saúde dos trabalhadores. Assim, a partir de então, o adulto passou a ter o direito de ser visto pela saúde pública:

em sua condição de trabalhador, o que implica conhecer a situação de trabalho, ou seja, não apenas o processo de produção em si, mas também o processo de produção e (re)-produção das relações sociais de produção. (CONSELHO FEDERAL DE PSICOLOGIA, 2008b, p. 16)

Todavia, apesar da garantia constitucional, foram raros os municípios ou estados que efetivamente implantaram tal programa na sua rede de saúde até meados da última década. Conforme afirmam Maeno e Carmo (2005), "mesmo com todo aparato legal definindo responsabilidades, os gestores federais, estaduais e municipais ignoraram solenemente essa área durante anos” (p. 270).

Após a criação do SUS, os poucos PSTs existentes foram sendo gradativamente transformados em Centros de Referência em Saúde do Trabalhador (atualmente, chamados nacionalmente de Cerests). Mas foi somente a partir de 2002 que o Ministério da Saúde efetivou a institucionalização de uma Política Nacional de Saúde do Trabalhador mediante portarias que criam a Rede Nacional de Atenção Integral à Saúde do Trabalhador (Renast) com o objetivo de "integrar a rede de serviços do SUS, voltados à assistência e à vigilância, para o desenvolvimento das ações de saúde do trabalhador" (BRASIL, 2005a). Desse modo, foram definidas ações que deveriam ocorrer da atenção básica à assistência de alta complexidade e também foram estabelecidas ações de promoção e educação em saúde do trabalhador e de vigilância em saúde do trabalhador (BRASIL, 2005b).

O "eixo integrador" da Renast foi o estabelecimento de uma "rede regionalizada de Centros de Referência em Saúde do Trabalhador - Cerest”, os quais teriam "a atribuição de dar suporte técnico e científico às intervenções do SUS no campo da Saúde do Trabalhador" (BRASIL, 2006). Para criar essa rede, a principal estratégia adotada foi muito parecida com aquela utilizada na política de Saúde Mental: o incentivo financeiro para os municípios e estados criarem ou aprimorarem unidades especializadas. E se na Saúde Mental o incentivo visava à ampliação do número de CAPS, na Política de Saúde do Trabalhador, o foco esteve na implantação e implementação de Cerests.
Entretanto, é necessário ressaltar que, assim como ocorreu na Saúde Mental, essas medidas também não garantiram a inclusão de ações de Saúde do Trabalhador na atenção básica e na vigilância. Essa integração continua sendo um dos grandes desafios do SUS e, vale dizer, não somente nos níveis municipais ou locais, mas em todas as esferas de governo. Mesmo no Ministério da Saúde, o diálogo entre as áreas ainda parece difícil. As proposições da Renast não são refletidas nas portarias ministeriais que normatizam a atuação das ESF, por exemplo. As diretrizes propostas para essa política para a atenção básica não incluem nenhuma estratégia para o enfrentamento de problemas que envolvem a relação saúde-trabalho-doença. E, se é assim no nível federal, o que se pode esperar dos níveis municipal e local?

Outro aspecto a ser destacado diz respeito ao fato de que, apesar da Renast, ainda hoje as concepções de grande parte dos profissionais e gestores do SUS sobre a saúde do trabalhador reproduzem a ideologia dominante na sociedade. Nos mais variados serviços de saúde, observa-se a presença marcante de um discurso que naturaliza a ocorrência dos acidentes e doenças no trabalho. Não é raro ouvir-se, por exemplo, falas que atribuem aos trabalhadores com queixas de saúde que podem estar relacionadas ao trabalho a pecha de “aproveitadores" e "preguiçosos" e outras que atribuem a causa dos acidentes de trabalho aos atos inseguros ${ }^{6}$ dos trabalhadores.

Infelizmente, essas concepções podem ser encontradas, inclusive, entre profissionais dos próprios Cerests. Enquanto as equipes dos primeiros PSTs eram integradas por "militantes", que tendiam a ter um olhar crítico para o processo saúde-doença-trabalho (LACAZ, 1996), os novos serviços criados após a Renast contam com profissionais que não necessariamente tinham interesse pela área e, não raro, sequer a conheciam anteriormente. Vale ressaltar que esse problema é agravado pelo fato de grande parte dos municípios, influenciada pela cultura hegemônica, exigir título de especialista em medicina do trabalho nos editais de contratação de médicos para os Cerests. ${ }^{7}$

Desse modo, arriscamo-nos a dizer que, se a falta da compreensão do processo saúde-doença como um fenômeno social tem repercussões na atenção à saúde mental, na saúde do trabalhador ela tem consequências ainda mais sérias. Devemos lembrar que as ações nesta área, sejam no plano assistencial ou da proteção, se dão diretamente no núcleo do sistema capitalista, ou seja, na relação capital-trabalho.

Outra dificuldade que envolve a área de Saúde do Trabalhador no SUS refere-se às ações de vigilância em ambientes de trabalho. É bastante frequente que

\footnotetext{
${ }^{6} \mathrm{O}$ conceito de ato inseguro aplica-se para responsabilizar os próprios trabalhadores pelos acidentes de trabalho de que são vítimas (OLIVEIRA, 1997). Geralmente são atribuídas explicações para ocorrência dos acidentes que se sustentam em concepções que incluem erros humanos, distração, fadiga e até ganhos secundários.
}

${ }^{7}$ A formação nessa especialidade médica ainda é marcadamente voltada para a atuação em empresas e calcada na visão do "ato inseguro". 
as empresas, especialmente de grande porte, questionem de forma sistemática as medidas punitivas que lhes são aplicadas pelo SUS quando situações de risco à saúde dos trabalhadores são identificadas no seu ambiente e/ou processo de trabalho. Tal fato cria situações de muito desgaste para as equipes de saúde e indica a necessidade do preparo dos aparatos jurídicos e administrativos do SUS para a sustentação das sanções impostas.

Tendo em vista esse pressuposto, é compreensível que as ações de vigilância em saúde do trabalhador se concentrem em problemas que podem ser mais facilmente provados, como é o caso dos riscos encontrados no ambiente de trabalho, especialmente aqueles que podem levar a acidentes. Além da visibilidade do risco, há outras razões objetivas para essa priorização, as quais arrolamos aqui: as ações de vigilância permitem a utilização de uma metodologia mais focada (BINDER; ALMEIDA, 1997; ALMEIDA, 2006) e têm grande impacto sobre a mortalidade de trabalhadores; a ocorrência de um acidente de trabalho sensibiliza mais a população leiga do que as doenças crônicas (especialmente aquelas menos visíveis, como as LER/DORT e o adoecimento mental); a repercussão dos acidentes de trabalho gera mais fortemente uma publicidade negativa para as empresas (SILVA; FISCHER, 2008), que, por isso, resistem menos às medidas impostas ou sugeridas pelos profissionais do SUS.

Já a “organização do trabalho" - que, vale dizer, é a responsável por muitos problemas de saúde mental relacionados ao trabalho - envolve aspectos subjetivos e, consequentemente, mais difíceis de serem demonstrados. Talvez por esse motivo observem-se bem menos relatos de ações de vigilância concernentes a esse aspecto. As respostas a algumas questões, como "qual é o ritmo aceitável para uma esteira de produção de fogões?”, "qual é o número de trabalhadores adequado para produzir "X” automóveis?”, “qual é o limite para que um chefe aplique sanções aos seus subordinados?”, dependem de uma ampla análise de cada processo de trabalho e são sempre referentes ao caso específico, dificilmente podendo ser generalizadas. Nesses casos, a objetivação se dá pelas consequências (número de trabalhadores adoecidos, por exemplo) e não pela extrapolação de um "limite de tolerância" estabelecido por lei, o que torna a tarefa de vigilância bastante complexa.

Essa complexidade da área e os conflitos que permeiam suas ações parecem ser fatores que ajudam a explicar porque as preocupações e as ações de Saúde do Trabalhador ainda estão concentradas nos Cerests. No entanto, conforme é discutido em outros artigos desta coletânea, o contexto atual do mundo do trabalho tem sido responsável por uma grande elevação do número de doenças do trabalho, especialmente o adoecimento e o sofrimento psíquico. Desse modo, mais do que em qualquer outra época, esse se configura como um problema de saúde pública que exige ações integradas que envolvam uma articulação de toda a rede de serviços que compõem o SUS.

\section{As dificuldades de integração entre as áreas de Saúde Mental e de Saúde do Trabalhador}

Os aspectos discutidos até aqui indicam que ainda existem muitos obstáculos que devem e podem ser superados para a atenção adequada à saúde mental relacionada ao trabalho no âmbito do SUS. Mas, se há dificuldades específicas de cada uma das duas áreas, os problemas que envolvem ambas estão ainda mais longe de uma atenção, se não plena, pelo menos aceitável. Nesse sentido, arriscamo-nos, aqui, a levantar alguns pontos que entendemos serem importantes para a análise dessa conjuntura. Antes, é importante esclarecer que este ensaio focaliza a interface saúde mental e saúde do trabalhador, sem, contudo, pretender abarcar a amplitude de questões que afetam as duas áreas. Trata-se de pontuar dificuldades que se apresentam no momento em que se objetiva superar modelos que foram hegemônicos durante séculos e implementar políticas públicas intrassetorias considerando as características de cada território.

Nesse sentido, o primeiro aspecto a ser destacado diz respeito ao gerenciamento dos serviços e das áreas programáticas. Deve-se lembrar de que, desde sua incorporação no sistema de saúde, tanto a Saúde Mental como a Saúde do Trabalhador tiveram coordenações distintas em todos os níveis do SUS (Ministério da Saúde e Secretarias Estaduais e Municipais de Saúde, especialmente de municípios de grande porte), estando ambas apartadas da gestão da atenção básica. Desse modo, as ações de cada uma dessas áreas se pautaram mais fortemente nas suas próprias necessidades e especificidades. Conforme apontado anteriormente, a Saúde Mental concentrou-se na consolidação da reforma psiquiátrica, priorizando a implantação dos CAPS, e a Saúde do Trabalhador ainda busca conquistar o reconhecimento da relação entre o trabalho e o processo saúde-doença.

Assim, a integração entre os serviços também se configura como outra importante dificuldade. A centralização da Saúde Mental nos CAPS, e da Saúde do Trabalhador nos Cerests parece aumentar a distância entre as duas áreas programáticas e dificultar o estabelecimento de ações conjuntas com relação ao adoecimento/ sofrimento psíquico relacionado ao trabalho.

Ainda que, nas leis e portarias, esteja explicitado que o SUS deve se pautar, entre outros princípios, na integração entre os diversos níveis, na intersetoridade e na integralidade, na prática, isso tem ocorrido apenas em experiências pontuais. No caso da Saúde do Trabalhador, muitas vezes, parece haver mais abertura de outros órgãos públicos que estão fora do SUS para a interlocução com os Cerests - como Ministério do Trabalho, Ministério Público do Trabalho etc. - do que da própria rede de saúde.

Também é importante lembrar que tanto a área de saúde mental, como a de saúde do trabalhador são bastante complexas e têm, ambas, um forte componente social. Por isso, pode-se dizer que existe um consenso entre teóricos do campo das políticas públicas de que, 
para o enfrentamento adequado dos problemas dessas áreas, são necessárias equipes multiprofissionais (AMARANTE, 1995; LACAZ, 1996; SCARCELLI, 1998), o que, evidentemente, fica ainda mais imperativo no caso de um tema que diz respeito a ambas.

Tal premissa parece dificultar a atenção a essa questão, especialmente na rede básica, com a atual conformação das equipes da ESF. Conforme afirmamos anteriormente, acreditamos que esse fato - somado à carência crônica de profissionais na área da saúde pública, à enorme gama de problemas a serem enfrentados no cotidiano dessas equipes e à formação dos profissionais de saúde mais voltada para as "tecnologias duras" do que para as "tecnologias leves" (MERHY, 1997) ${ }^{8}-$ não favorece a atenção aos problemas de saúde mental e de saúde do trabalhador pela rede básica. E, a partir dessa constatação, não é difícil deduzir que problemas de saúde que se situam na intersecção entre duas áreas sejam ainda menos priorizados.

Deve-se lembrar, ainda, de que a população leiga, de uma forma geral, também não identifica a saúde mental relacionada ao trabalho como um problema a ser enfrentado pela saúde pública. Ao contrário de outras questões tradicionalmente vinculadas às unidades básicas de saúde (como a saúde da criança ou da mulher, por exemplo), essa, raramente, aparece como uma demanda da população de um determinado território para a equipe de saúde.

Mas, além das dificuldades da rede básica, parece-nos que a própria política de saúde mental não propicia condições para a atenção aos problemas de saúde mental relacionada ao trabalho. Vale lembrar que essa política prioriza o atendimento de casos graves e/ou agudos - que deve ocorrer nos CAPS e nos hospitais - e a atenção aos casos "leves" - que deve se dar nas equipes de saúde da família, com suporte dos NASFs. Entretanto, os casos que poderíamos chamar de "intermediários" - que incluem a maioria daqueles de saúde mental relacionada ao trabalho - não contam, em geral, com um sistema estruturado para seu atendimento.

Um segundo aspecto da política de Saúde Mental que também deve ser levantado aqui diz respeito à reabilitação psicossocial, que é um dos objetivos buscados. Amarante (1995) lembra que, no contexto da reforma psiquiátrica:

o tratamento deixa de ser a exclusão em espaços de violência e mortificação para tornar-se criação de possibilidades concretas de sociabilidade. (p. 494)

Nesse sentido, a proposta antimanicomial prevê que aquele que antes era o "doente" excluído, agora passe a ser sujeito da sua própria existência (AMARANTE, 1995). Para atingir esse objetivo, o trabalho, enquanto atividade social, torna-se um importante instrumento para a emancipação do indivíduo, com a recuperação da sua cidadania, e para a reconstrução de laços e redes sociais, podendo se dar de diversas formas. A constituição de cooperativas sociais, por exemplo, pode ter a dupla função de colaborar na recuperação da saúde mental e possibilitar um contexto em que o trabalhador seja dono de sua força de trabalho.

No entanto, no modelo capitalista em que vivemos, a principal representação do trabalho é, ainda, o vínculo de emprego. E se retomamos o que foi dito anteriormente a respeito da falta de um olhar crítico para a relação capital-trabalho por parte de muitos profissionais de saúde, não é difícil deduzir que a inserção dos usuários dos serviços de saúde mental em um posto de trabalho com carteira assinada acabe sendo um importante objetivo da reabilitação que, quando atingido, torne-se um símbolo do tratamento bem-sucedido.

Desse modo, apesar de ser coerente a proposta de que o trabalho seja um dos instrumentos de reabilitação psicossocial na área de saúde mental, tal inserção deve ser pensada de forma crítica. Projetos que tratem a inclusão no trabalho sem considerar o contexto social que produz adoecimento e sofrimento psíquico podem incorrer no erro de ver a inserção no mercado de trabalho, seja de que tipo for, sempre como um fator positivo para o sujeito. Assim, os pacientes podem, por exemplo, ser incentivados a se empregarem em ocupações que em nada colaborarão para sua recuperação ou, o que é pior, a desenvolverem atividades potencialmente lesivas à sua saúde.

Ao desconsiderar a vida laboral anterior de seus pacientes, as equipes de saúde mental também podem tratar problemas relacionados ao trabalho como se esses fossem exclusivamente de ordem intrapsíquica. Nesse sentido, teriam um papel iatrogênico na medida em que colocam exclusivamente no indivíduo a razão do adoecimento e, consequentemente, o foco do "tratamento" no plano pessoal. Além disso, ao olhar apenas para o indivíduo e não para a coletividade, deixam de lado um dos eixos do SUS, que é a prevenção, colaborando com a manutenção de uma situação que pode afetar a saúde mental de outros trabalhadores.

Por outro lado, também devemos considerar que a já citada dificuldade para avaliar e demonstrar situações de risco relacionadas à organização dos processos de trabalho tem consequências diretas para a adequada atenção a questões de saúde mental relacionadas ao trabalho. E se isso é observado no âmbito da vigilância, também ocorre no nível da atenção à saúde. $\mathrm{O}$ estabelecimento do nexo causal entre o trabalho e o adoecimento, que nem sempre é simples, torna-se ainda mais complexo nos casos de saúde mental, que envolve diagnósticos encontrados com grande frequência na população em geral e não pro-

\footnotetext{
${ }^{8}$ Merhy tem focalizado esse tema em muitas de suas publicações. Segundo ele, a "tecnologia dura" envolve ações pautadas em equipamentos e exames, enquanto as "tecnologias leves" dizem respeito a um olhar mais para o social e às relações que se estabelecem entre os profissionais de saúde e a população.
} 
blemas reconhecidos como doenças profissionais. Como afirmar, por exemplo, que um caso de depressão ou de síndrome do pânico está relacionado ao trabalho? Certamente, a resposta nos remete aos desafios da integração dos serviços em rede, da responsabilização das equipes e da implementação dos projetos terapêuticos em equipes multidisciplinares, de forma a contribuir para uma atenção integral pautada na análise clínica, e da situação de trabalho dos envolvidos, bem como de outros determinantes e condicionantes sociais da saúde.

Muitos dos pontos levantados aqui são passíveis de contestação, mas dificilmente seria questionada a afirmação de que a integração dessas duas áreas programáticas, seja entre si ou com as áreas tradicionais do SUS, ainda é muito tênue, dificultando sobremaneira a atuação sobre problemas de saúde que se encontram na fronteira entre ambas, como é o caso da saúde mental relacionada ao trabalho.

Para essa integração parece ser necessário "desconstruir" tanto a cultura manicomial como a cultura da positividade do trabalho no contexto capitalista e a naturalização dos acidentes e doenças decorrentes do trabalho (entre os profissionais e gestores de saúde ou na população em geral). Também é necessário superar a concepção individualizante e medicalizante que permeia a compreensão desses fenômenos (SATO, 1993; ALMEIDA, 2001; BRANT; MINAYO-GOMEZ, 2007).

Desse modo, entendemos que, para que se possa avançar na construção do SUS, radicalizando seus princípios, é fundamental que o sofrimento/adoecimento psíquico relacionado ao trabalho não seja apenas um problema de uma área ou, ainda pior, de um tipo de unidade de saúde e, sim, de todos os níveis do Sistema de Saúde.

\section{Conforme afirmam Scarcelli e Alencar (2009):}

[...] não temos dúvidas de que os problemas estruturais só poderão ser resolvidos a partir da superação das contradições do próprio sistema de produção capitalista. Mas isto não nos retira a responsabilidade de continuar buscando soluções, mesmo pontuais, e principalmente de desvendar as complexidades de nossa realidade social. (p. 8)

\section{Atenção à saúde mental e trabalho nos diferentes níveis de atenção do SUS: pos- sibilidades e desafios}

Apesar das dificuldades apontadas até aqui, existem experiências que demonstram que a atenção à saúde mental relacionada ao trabalho pode ocorrer no SUS de formas criativas e integradas. Assim, neste item, vamos apresentar alguns exemplos de ações que mostram como a integração entre as áreas e/ou níveis do SUS possibilita uma atenção mais adequada a esse problema de saúde. Também vamos apontar alguns desafios que ainda necessitam ser superados.

\section{Atenção Básica: porta de entrada do SUS}

De acordo com a organização do SUS, no nível da atenção básica, as estratégias de cuidado e proteção à saúde se voltam às necessidades da população no território com vistas a garantir universalidade, acessibilidade, vínculo, integralidade e responsabilização. Parte-se do princípio de que o reconhecimento do território e dos condicionantes do processo saúde-doença, isto é, rede de saneamento, água tratada ou fontes alternativas, meio ambiente, incluindo o de trabalho, faixa etária, nível de escolaridade, ocupações, doenças etc., retrata as reais condições de vida e saúde da população. Esta perspectiva de gestão da saúde implica a construção de respostas no território, o compartilhamento das responsabilidades e a articulação de recursos comunitários. Dessa forma, se a territorialização é um importante pressuposto do trabalho das equipes de atenção básica (BRASIL, 2009), também é essencial no caso da saúde mental relacionada ao trabalho, como se pode exemplificar a partir de uma situação hipotética apresentada a seguir, que, infelizmente, ainda não é comum.

Pensemos em algumas Unidades Básicas de Saúde ou equipes da ESF que recebem diversos usuários com queixas de tonturas, mal-estar, dores de cabeça, irritabilidade e agressividade imotivadas, entre outros sintomas. Inicialmente, os profissionais não relacionam as queixas à ocupação e atribuem os sintomas às características pessoais e familiares das pessoas atendidas, buscando discutir os casos com os profissionais de referência em saúde mental do NASF.

Aqueles que participam das discussões observam que os relatos são muito similares em todos os casos e remetem à mesma situação de trabalho, a qual se caracteriza pela exposição a produtos neurotóxicos em uma empresa química estabelecida no território de uma das unidades. Ao pesquisar os efeitos dos produtos referidos pelos usuários, a equipe verifica que eles são compatíveis com os sintomas apresentados e, ainda, relacionam-se com os relatos e as observações de que a empresa descarta substâncias químicas no solo.

A partir dessa constatação, a atenção à saúde desses usuários muda. Além do estabelecimento de um projeto terapêutico individual que leve em conta a possível contaminação de cada um e sua relação com os sintomas neuropsíquicos, também é buscada uma articulação com o serviço de Vigilância em Saúde e o Cerest de referência para a realização de ações de vigilância naquele ambiente de modo a eliminar a "fonte" do risco à saúde da população trabalhadora e moradora do local. Dessa forma, a ação da equipe não se restringe à atenção individual mais adequada às características daquele processo de adoecimento. Ela também se expande para a prevenção com um olhar para o território, dando sentido aos princípios buscados com a ideia da ESF. Esta situação retrata o desenvolvimento de uma ação integrada e intrassetorial que contempla as necessidades e as realidades de saúde local objetivando controlar determinantes, risco e danos à saúde daquela população. 
Outro exemplo hipotético, que, não obstante, é comum nos dias atuais, pode ser o de uma empresa que encerra suas atividades em um determinado local ou muda suas instalações para outra cidade. Com o desemprego gerado por esse fato, imediatamente aumenta a demanda de usuários no serviço de saúde próximo com queixas de sofrimento mental, perda da perspectiva de vida, desânimo, tristeza, sentimento de inutilidade, ansiedade. Nesse caso, uma intervenção que desconsidere a causa do sofrimento poderá implicar uma abordagem puramente medicamentosa, sem a possibilidade de ressignificação da experiência vivida e o olhar sobre a subjetividade das pessoas (TERRA, et al., 2006; FARINA; NEVES, 2007). Todavia, ao olhar para o território tendo como pano de fundo a concepção de que a saúde integra fatores sociais, os profissionais poderão compreender o processo em que se originou esse sofrimento e pensar em outros tipos de ações junto à comunidade.

\section{O estabelecimento do nexo causal: um desafio que exige integração intrassetorial no SUS}

Conforme vimos, uma difícil demanda que se apresenta ao SUS, por parte dos trabalhadores, especialmente aos Cerests no contexto atual, consiste na necessidade de estabelecimento do nexo causal entre o sofrimento mental e o trabalho. Frequentemente, essa demanda retrata um percurso em que os trabalhadores já foram atendidos por diversos profissionais de saúde das empresas e da rede pública e apresentam o relato de aspectos da organização e das condições de trabalho que desencadearam ou agravaram o processo de adoecimento.

Frequentemente, a procura do primeiro atendimento relaciona-se à queixa física, com destaque para as dores musculoesqueléticas (casos de LER/DORT), em que a condição de trabalho exige movimento repetitivo, sem pausas ou com pausas controladas, posturas inadequadas em função do mobiliário, longos períodos em pé ou sentado, pressão para cumprimento de metas, exigência de produtividade e, por vezes, clima de ameaças. Porém, é bastante comum que, ao descreverem seus sintomas, esses trabalhadores também relatem características que indicam sofrimento/ adoecimento mental, tais como sintomas depressivos, apatia, irritabilidade, isolamento do círculo social e familiar, baixa autoestima, dificuldade de concentração, desesperança, os quais, muitas vezes, são tão ou mais graves do que a queixa física apresentada inicialmente, mas não têm o mesmo reconhecimento social (SATO; BERNARDO, 2005).

Quando esses trabalhadores chegam aos Cerests ou à rede básica, não raro são atendidos unicamente com relação aos seus sintomas físicos, desconsiderando a importância do trabalho no desenvolvimento dos sintomas psíquicos. Mas, conforme já foi discutido na seção anterior, o contrário também ocorre. Existem trabalhadores com problemas de saúde mental relacionada ao trabalho que são atendidos em serviços de saúde mental sem que essa relação seja estabelecida. Nesses casos, é fundamental a integração dos serviços especializados de Saúde Mental e de Saúde do Trabalhador.

Um exemplo desse tipo de relação é o de uma situação real ocorrida em um município do interior paulista. Em 2008, uma terapeuta ocupacional do Cerest Regional com experiência na área de reabilitação profissional foi convidada a ajudar na condução de um grupo de pacientes de um CAPS com o objetivo de discutir o retorno ao trabalho. Na perspectiva dos profissionais do CAPS, tratava-se apenas de "pacientes de saúde mental" cujo adoecimento não era associado à sua atividade anterior e que se encontravam em uma fase de recuperação que lhes permitia pensar no retorno ao trabalho. No entanto, ao iniciar o grupo, a terapeuta ocupacional observou que os problemas apresentados por alguns daqueles pacientes pareciam ter relação com sua atividade laboral. Propôs, então, a realização de uma discussão desses casos pela equipe do CAPS juntamente com ela e a psicóloga do Cerest.

Foram estabelecidas algumas atividades prévias às discussões. A profissional da saúde do trabalhador, com base no roteiro de acolhimento utilizado naquele serviço, fez uma primeira entrevista com os usuários cujo diagnóstico poderia ser relacionado ao trabalho. O objetivo era levantar aspectos de sua história laboral que pudessem estar relacionados ao adoecimento. Já à equipe do CAPS coube fazer um levantamento dos dados anotados no prontuário do paciente.

Depois de realizadas essas tarefas, as duas "leituras" dos casos foram confrontadas em reunião. Nessas discussões, observou-se a enorme distância entre o olhar das duas equipes. Um dos usuários, por exemplo, era um vigilante que havia tido o primeiro surto psicótico alguns meses após a empresa onde trabalhava sofrer um assalto durante seu turno de trabalho, no qual feriu gravemente um dos ladrões e ele mesmo quase fora atingido. Depois desse surto, ele teve uma internação de curta duração em um hospital psiquiátrico e, em seguida, foi encaminhado ao CAPS. Apesar de a hipótese do nexo com o trabalho ser bastante evidente para as profissionais da Saúde do Trabalhador, essa associação nunca havia sido pensada pela equipe do CAPS. Aliás, sequer constava algum dado sobre o histórico de trabalho no prontuário do paciente. Ali, a história iniciava-se com sua internação acrescida de poucos dados de sua vida familiar anterior.

Também ficaram evidentes as diferenças de concepções. Enquanto alguns profissionais do CAPS focavam os problemas de saúde mental no intrapsíquico e discutiam a atividade de trabalho como uma escolha pessoal, as profissionais da saúde do trabalhador apontavam os aspectos sociais, indicando o trabalho como um fator fundamental no diagnóstico e no encaminhamento. Tal observação é corroborada pela afirmação de Lima (2005) de que a polêmica em torno do nexo causal é fruto das distintas concepções teóricas sobre a gênese da doença mental, que, para alguns, advém de fatores essencialmente orgânicos (aqueles que defendem a tese da psicogênese), enquanto, para outros, é multideterminada, integrando fatores biopsicossociais. 
É interessante relatar que, após um amplo debate, nas reuniões da equipe do CAPS com as profissionais do Cerest, com relação ao nexo da doença apresentada pelo paciente com a sua vivência no trabalho, foi possível chegar a um consenso de que esse nexo, de fato, existia. Assim, foi designado um grupo menor composto por profissionais de ambas as unidades para o preenchimento da notificação do sistema de saúde (Sinan) $)^{9} \mathrm{e}$ da Comunicação de Acidente de Trabalho (CAT) e para os encaminhamentos junto ao Instituto Nacional do Seguro Social (INSS).

Outro aspecto a ser destacado é que a questão da cultura da positividade do trabalho também ficou bastante evidente entre muitos dos integrantes da equipe do CAPS, que viam a inserção no trabalho, qualquer que fosse ele, como um sinal da recuperação do paciente. No caso discutido aqui, o usuário era um vigilante com baixo nível de instrução formal. Para os profissionais que o acompanhavam do CAPS, a principal questão era que ele já tinha condições de voltar a trabalhar, mas em uma atividade que não envolvesse armas. Assim, haviam sugerido a ele, com bastante naturalidade, que procurasse um emprego de ajudante de pedreiro - por ser uma atividade compatível com seu nível de instrução - sem considerar a complexidade do contexto que envolvia a relação entre o adoecimento do trabalhador, sua atividade e o sentido do trabalho para ele. A resistência em aceitar essa mudança de trabalho era interpretada unicamente com base nas características intrapsíquicas do paciente. Foi somente após a discussão com as profissionais da saúde do trabalhador que essa questão foi reavaliada pela equipe do CAPS e foram pensadas outras possibilidades de encaminhamento.

Além do caso descrito, alguns outros vêm sendo discutidos e tal atividade comprova a importância da aproximação entre esses dois tipos serviços para a ação efetiva do SUS sobre os problemas de saúde mental relacionados ao trabalho. Deve-se lembrar que o paciente citado acima havia chegado ao CAPS e não ao Cerest e, se essa integração não tivesse ocorrido, provavelmente ainda constaria das estatísticas e da rotina do SUS apenas como um caso "comum" de saúde mental, sem que a questão da relação do adoecimento com o trabalho sequer fosse levantada como hipótese. $\mathrm{E}$ vale dizer que esse deve ainda ser o caso de muitos outros trabalhadores adoecidos nesse e em outros municípios.

Essas experiências encontram ressonância na afirmação de Jardim e Glina (2000) de que a complexidade da investigação diagnóstica em saúde mental e trabalho deve combinar diferentes técnicas e saberes. As autoras afirmam que, nesse processo, torna-se imprescindível perguntar sobre o trabalho, realizar uma anamnese ocupacional, levantar aspectos da organização do trabalho, identificar as exigências físicas e mentais, inquirir so- bre a percepção do trabalhador a respeito dos riscos e, sempre que possível, observar o posto de trabalho, as condições ambientais e o processo de trabalho.

Também é importante registrar que, em 2001, o Ministério da Saúde publicou um manual no qual apresenta diretrizes para o estabelecimento do nexo entre trabalho e adoecimento e que inclui um capítulo dedicado à saúde mental (BRASIL, 2001b). Tomando como base uma adaptação da classificação proposta por Schilling (1984), o manual divide a relação do trabalho com o adoecimento em três categorias: trabalho como causa necessária (Tipo I), como fator de risco contributivo de doença de etiologia multicausal (Tipo II) ou como fator desencadeante ou agravante de doença preexistente (Tipo III). Ainda que consideremos as limitações dessa classificação e as dificuldades de enquadrar os casos da saúde mental relacionados ao trabalho em uma ou outra categoria, avaliamos que ela é útil no sentido de esclarecer que o nexo entre o trabalho e qualquer tipo de adoecimento pode se dar em diferentes níveis e que todos devem ser notificados.

No caso da saúde mental, o trabalho como causa necessária para o adoecimento mental poderá ser identificado, sobretudo, nos casos de transtornos orgânicos de personalidade, transtornos cognitivos e outros sintomas decorrentes da exposição ocupacional a substâncias químicas tóxicas e a agentes físicos, como, por exemplo, chumbo, manganês e mercúrio. Podemos também incluir aqui os quadros de estresse pós-traumático decorrentes da exposição a um evento ou situação estressante de natureza excepcionalmente ameaçadora, como assaltos ocorridos no local de trabalho, e, ainda, de transtornos do ciclo vigília-sono, decorrentes de regime de revezamento de turnos.

Entre os casos em que o nexo se dá porque o trabalho é um fator contributivo para doença de etiologia multicausal, estão, por exemplo, a síndrome de burnout e outros problemas de saúde mental relacionados à vivência prolongada em contextos de trabalho com altos níveis de exigência, ou em ambientes que passam por transformações organizacionais constantes ou, ainda, à submissão a ritmos de trabalho muito intensos.

Finalmente, o trabalho pode ser considerado provocador de uma doença já estabelecida no caso de trabalhadores alcoolistas ou com transtornos neuróticos especificados, que estavam controlados e tiveram recidiva devido ao trabalho.

Os estudos de Lima $(2005,2007)$ e Vieira (2009) registram a relevância e a complexidade de se estabelecer a relação causal entre o trabalho e os transtornos mentais e apontam que superar este desafio é fundamental e decisivo para a proteção da saúde dos trabalhadores, que, vale lembrar, faz parte das diretrizes do SUS.

\footnotetext{
${ }^{9}$ Esse sistema de notificação foi estabelecido pela Portaria GM/MS no 777 e dispõe sobre os procedimentos técnicos para a notificação compulsória pelo SUS de determinados agravos à saúde, incluindo a saúde mental relacionada ao trabalho. Importante registrar que esse sistema de notificação abrange todos os tipos de trabalhadores, quer estejam inseridos no mercado de trabalho formal ou no informal.
} 


\section{Evento sentinela ${ }^{10}$ : investigação e prevenção}

A ocorrência de um evento em determinado local de trabalho sinaliza aos serviços de saúde a necessidade de uma intervenção. Um evento sentinela pode ser, entre outros, um acidente de trabalho ou a constatação de um número elevado de trabalhadores de um mesmo local com determinado diagnóstico.

Um exemplo interessante de como um evento desse tipo pode ajudar na atuação do SUS sobre a saúde mental relacionada ao trabalho refere-se a um caso ocorrido na região metropolitana de São Paulo. Ele se iniciou com a constatação da psiquiatra do convênio de uma empresa pertencente a uma grande rede varejista de que os trabalhadores dessa empresa apresentavam queixas de saúde mental similares.

Esses trabalhadores referiam-se a desânimo, falta de interesse geral, insônia, excesso de somatizações, pensamentos suicidas, cansaço físico e mental, fadiga, nervosismo, irritação exacerbada, tristeza e todos faziam uso de medicação. Descreviam também a ocorrência de assaltos no trabalho, a pressão psicológica para atingir as metas, medo de demissão e as mudanças gerenciais implementadas por uma nova administração. Além disso, a médica observou que o tempo de recuperação e afastamento do trabalho devido ao adoecimento nesse grupo era superior a outros casos com o mesmo diagnóstico.

Sem familiaridade com o mundo do trabalho, a profissional buscou amparo teórico-técnico para sua conduta junto ao Cerest estadual, que propôs ao serviço de referência em saúde do trabalhador do município um trabalho conjunto. As equipes de ambos os serviços constataram tratar-se de um problema regional, uma vez que a empresa possuía lojas em diversos municípios. Desse modo foram convidados os Cerests, os serviços de vigilância à saúde dos demais municípios e o sindicato da categoria profissional para uma ação regional articulada.

Foi estabelecido um plano de intervenção conjunto, que incluía a realização de entrevistas com os trabalhadores pelos profissionais do Cerest; grupos de orientação com o intuito de que os trabalhadores refletissem sobre o processo de adoecimento e suas peculiaridades; e levantamento de dados sobre a empresa junto a outros Cerests e ao INSS.

Importante registrar que, além do caráter regional, o trabalho foi concebido por um grupo interdisciplinar: psicólogos, médicos, assistentes sociais, técnicos de segurança do trabalho, engenheiros, fonoaudiólogos. Portanto, os desafios se apresentavam tanto em relação à demanda, quanto à organização do grupo e à metodologia de trabalho.

Os dados foram analisados pela equipe ampliada, constatando-se que os trabalhadores apresentavam alto nível de sofrimento mental, sem história pregressa, que associavam às características da organização do trabalho. Foram realizadas devolutivas dos dados obtidos aos trabalhadores e indicadas condutas individuais, como, por exemplo, abertura de comunicação de acidente de trabalho (CAT), encaminhamento para atendimento psicológico e acompanhamento no retorno ao trabalho. Simultaneamente, foram planejadas ações de vigilância à empresa que contemplaram a verificação do cumprimento das normas de saúde e segurança no trabalho, bem como a aplicação de um questionário aos trabalhadores e supervisores para a caracterização dos aspectos relacionados à organização do trabalho.

Esse caso possibilita observar como a suspeita de uma profissional de que problemas de saúde mental poderiam estar relacionados ao trabalho configurou-se como um evento sentinela que resultou, por um lado, em atividades de vigilância na empresa com a participação do movimento sindical e de diferentes serviços do SUS e, por outro, na organização dos serviços para a atenção à saúde dos trabalhadores. E vale dizer que, se essa demanda foi identificada pela psiquiatra do convênio de uma empresa, poderia tê-lo sido por um profissional do SUS.

Esse exemplo também levanta uma questão comum na área de saúde do trabalhador: como e o que "olhar" nos aspectos relativos à organização do trabalho em um processo de vigilância em saúde do trabalhador e, principalmente, em um caso como o relatado aqui, no qual a saúde mental está em foco? A experiência demonstra como os profissionais encontram dificuldades no levantamento das condições subjetivas em que ocorre o trabalho e o modo como este se organiza, porque, em geral, há pouca participação dos trabalhadores para o reconhecimento dos fatores de risco relativos a essa questão.

Consideramos que uma metodologia essencial relativa à temática foi utilizada na Reforma Sanitária Italiana, denominada Modelo Operário Italiano (ODDONE et al., 1986; SATO; VALENTE; FREITAS, 1993). Este modelo tinha como premissas a formação de grupos homogêneos, a experiência ou subjetividade operária, a validação consensual e a não delegação, priorizando a participação dos trabalhadores nas ações de controle da saúde nos locais de trabalho, valorizando o conhecimento e a experiência do trabalhador.

A compreensão do universo de trabalho a partir da identificação, pelos trabalhadores, dos aspectos positivos e negativos que o conformam possibilita entender os impactos dos processos de trabalho na sua subjetividade. Importante ressaltar que a participação dos trabalhadores a que nos referirmos em nada tem a ver com as estratégias da gestão empresarial, que utiliza a cooperação e a participação dos trabalhadores como instrumentos de padronização das subjetividades (BERNARDO, 2009).

\footnotetext{
10 "Evento sentinela" é um termo aplicado a casos que servem de alerta para a possibilidade de ocorrência de agravos à saúde a uma coletividade. A constatação desse tipo de evento tem por finalidade acionar ações de prevenção.
} 
Para concluir este item, vale dizer que, nesse tipo de intervenção, que envolve uma escuta para os problemas vivenciados pelos trabalhadores, os profissionais de saúde mental podem ter muito a colaborar na equipe multiprofissional.

\section{Notificação compulsória de agravos à saúde do trabalhador}

Por muito tempo, os dados de adoecimento no trabalho basearam-se nas comunicações de acidente do trabalho (CAT), de preenchimento obrigatório nos casos de trabalhadores regidos pela Consolidação das Leis do Trabalho (CLT). Desta forma, os dados no INSS eram a fonte primordial para o conhecimento do perfil de adoecimento dos trabalhadores. Porém, esses dados apresentam diversas dificuldades para se alcançar esse fim. Inicialmente, deve-se lembrar de que se referem somente a pessoas inseridas no mercado formal e que são seguradas do INSS. Mas, além disso, não costumam retratar a realidade das doenças de saúde relacionadas ao trabalho, especialmente os transtornos mentais. Estes aparecem nas estatísticas do INSS como uma das principais causas de afastamento do trabalho, mas a maioria sem nexo com o trabalho, o que faz pensar em uma subnotificação. ${ }^{11}$

Diante desta realidade, muitos municípios instituíram, na rede municipal de saúde, fichas de notificação dos acidentes/doenças de trabalho de modo a incluir trabalhadores estatutários, autônomos, informais etc. nas estatísticas municipais de agravos relacionados à saúde dos trabalhadores. Dentre outras experiências, os Cerests de alguns municípios criaram e aprimoram as fichas denominadas Relatório de Atendimento de Acidente de Trabalho (RAAT), como, por exemplo, Diadema (GARBIN; KANASAWA; URTADO; 2007), Piracicaba (CORDEIRO et al., 2005), São Paulo e Rio Claro.

Mais recentemente, no entanto, essa questão também passa a fazer parte do cenário nacional. Assim, a notificação compulsória dos transtornos mentais relacionados ao trabalho é impulsionada por uma portaria do Ministério da Saúde (BRASIL, 2004), que institui um Sistema de Informação de Agravos de Notificação (Sinan) de doenças relacionadas ao trabalho, que pressupõe a articulação das ações dos Cerests com a rede de saúde.

Essa Portaria, juntamente com a regulamentação do fluxo das informações no Estado de São Paulo, por meio da Resolução no 63/09, da Secretaria de Estado da Saúde, traduz-se em uma estratégia de discussão sobre os agravos relacionados à saúde do trabalhador com a rede básica, serviços especializados, urgência e emergência, rede hospitalar (SÃO PAULO, 2009).

Entretanto, a experiência de atuação nos Cerest nos possibilita registrar que, de todos os agravos à saúde dos trabalhadores de notificação compulsória, os acidentes graves e fatais foram aqueles mais facilmente absorvidos na rotina dos serviços e, consequentemente, geraram dados para análise e sistematização. Já para os casos dos transtornos mentais, a realidade ainda é bem diferente. As dificuldades de articulação com a área programática de saúde mental, os obstáculos teórico-práticos dos profissionais em exercitar e confrontar o diagnóstico do transtorno mental e os embates com as empresas são entraves para que os registros de agravos à saúde mental relacionados ao trabalho sejam representativos daquilo que é vivenciado pelos trabalhadores.

Mas não temos dúvida sobre a importância de se buscar a implementação das notificações dos agravos à saúde mental relacionados ao trabalho para poder dar visibilidade a essa questão que se configura como um grave problema de saúde pública.

\section{Considerações finais}

Ao elegermos a categoria trabalho como central na dinâmica de vida das pessoas, esta se apresenta como uma possibilidade terapêutica, portanto com sua potencialidade integradora, criativa e de reconhecimento, perspectiva comumente utilizada na atenção em saúde mental, isto é, a possibilidade de reinserção social.

Neste sentido, Antunes (1995, p. 121) sustenta a dimensão essencial do trabalho:

Este por sua vez desenvolve-se pelos laços de cooperação social existentes no processo de produção material, em outras palavras, o ato de produção e reprodução da vida humana realiza-se pelo trabalho. É a partir do trabalho em sua cotidianidade que o homem torna-se ser social, distinguindo-se de todas as formas não humanas.

Por outro lado, salientamos que é intrínseco ao modo capitalista de organização do trabalho um potencial adoecedor, que repercute na saúde das pessoas, em especial na subjetividade do ser humano (BERNARDO, 2009; GARBIN, 2009) e esse é um aspecto ainda pouco assumido pelo SUS devido às dificuldades apontadas ao longo deste ensaio.

\footnotetext{
${ }^{11}$ É importante dizer que, a partir da entrada em vigor da Lei no 11.430 , de 26 de dezembro de 2006, do decreto no 6.042 , de 12 de fevereiro de 2007, o INSS passou a reconhecer doenças relacionadas ao trabalho mediante o estabelecimento de "nexo técnico epidemiológico" relacionado à atividade profissional exercida. Assim, "quando um trabalhador for afastado do trabalho por uma determinada doença que tenha significância estatística no ramo econômico a que pertence seu empregador, seu benefício será definido automaticamente pelo INSS como acidente de trabalho" (CONSELHO FEDERAL DE PSICOLOGIA, 2008b). Com isso, o número de registros de doenças mentais relacionadas ao trabalho no INSS aumentou mais de 1000\% de 2006 para 2007.
} 
Assim, entendemos que a integração entre os "olhares, saberes e experiências” das áreas de Saúde Mental e de Saúde do Trabalhador no SUS é urgente e fundamental para a superação da leitura individualizante e culpabilizante sobre o sofrimento mental relacionado ao trabalho que ainda predomina na sociedade e nos próprios serviços de saúde pública.

Buscamos também demonstrar que o potencial dos diversos níveis de atenção do SUS para o de- senvolvimento de ações sobre problemas de saúde mental relacionados ao trabalho é enorme. Para que isso ocorra, no entanto, ainda é necessário que essa questão seja, de fato, vista pelos gestores e profissionais do SUS em toda a sua dimensão e complexidade, envolvendo a militância dos profissionais e do movimento social que, historicamente, defenderam a proteção e o cuidado na área da saúde mental e da saúde do trabalhador.

\section{Contribuições de autoria}

Bernardo, M. H. e Garbin, A. de C. participaram igualmente de todas as etapas de elaboração do artigo.

\section{Referências}

ALMEIDA, I. M. de. Construindo a culpa e evitando a prevenção: caminhos da investigação de acidentes do trabalho em empresas e município de porte médio, Botucatu, São Paulo, 1997. 2001. 222 f. Tese (Doutorado em Saúde Ambiental)-Faculdade de Saúde Pública, Universidade de São Paulo, São Paulo, 2001.

. Trajetória da análise de acidentes: o paradigma tradicional e os primórdios da ampliação da análise. Interface, Botucatu, v. 10, n. 19, p. 185-202, jun. 2006.

AMARANTE, P. Novos sujeitos, novos direitos: o debate em torno da Reforma Psiquiátrica. Cadernos de Saúde Pública, Rio de Janeiro, v. 11, n. 3, p. 491-494, jul./set. 1995.

. Loucos pela vida: a trajetória da reforma psiquiátrica no Brasil. Rio de Janeiro: Fiocruz, 2000.

ANTUNES, R. Adeus ao trabalho? Ensaio sobre as metamorfoses e a centralidade do mundo do trabalho. São Paulo: Cortez; Campinas: Unicamp, 1995.

BERNARDO, M. H. Trabalho duro, discurso flexível: uma análise das contradições do toyotismo a partir da vivência de trabalhadores. São Paulo: Expressão Popular, 2009.

BINDER, M. C. P.; ALMEIDA, I. M. Estudo de caso de dois acidentes do trabalho investigados com o método de árvore de causas. Cadernos de Saúde Pública, Rio de Janeiro, v. 13, n. 4, p. 749-760, out. 1997.

BRANT, L. C.; MINAYO-GOMEZ, C. Dispositivos de transformação do sofrimento em adoecimento numa empresa. Psicologia em Estudo. Maringá, v. 12, n. 3, p. 465-473, 2007.

BRASIL. Ministério da Saúde. Portaria nº 189, de 19 de novembro de 1991. Define a necessidade de compatibilizar os procedimentos das ações de saúde mental com o modelo assistencial vigente. Diário Oficial [da] República Federativa do Brasil, Brasília, DF, 1991. Seção I, p. 284-295.
. Portaria SAS/MS no 224 , de 29 de

janeiro de 1992. Estabelece diretrizes e normas para a atendimento ambulatorial e hospitalar na assistência à saúde mental. Diário Oficial [da] República Federativa do Brasil, Brasília, DF, 1992. Disponível em: < http:// www.saude.mg.gov.br/atos_normativos/legislaçãosanitaria/estabelecimentos-de-saude/saude-mental/ PORTARIA_224.pdf $>$. Acesso em: 7 abr. 2011.

. Lei Federal no 9.867, de 10 de novembro de 1999. Dispõe sobre a criação e o funcionamento de Cooperativas Sociais, visando à integração social dos cidadãos. Diário Oficial [da] República Federativa do Brasil, Brasília, DF, 11 nov.1999. Disponível em: <http://portal.saude.gov.br/portal/arquivos/pdf/ Lei_9867.pdf>. Acesso em 7 abr. 2011.

. Lei Federal no 10.216, de 6 de abril de 2001. Dispõe sobre a proteção e os direitos das pessoas portadoras de transtornos mentais e redireciona o modelo assistencial em saúde mental. Diário Oficial [da] República Federativa do Brasil, Brasília, DF, 7 abr. 2001a. Disponível em: <http:/portal.anvisa.gov.br/wps/wcm/ connect/Ofa96700431cd5c7ba16ba9c579bb600/ $\mathrm{LEI}+\mathrm{N} \% \mathrm{BA}+10.216-2001 . p d f ? \mathrm{MOD}=\mathrm{AJPERE}>$. Acesso em: 7 abr. 2011.

- Ministério da Saúde. Doenças relacionadas ao trabalho: manual de procedimentos para os serviços de saúde. Brasília: Ministério da Saúde, 2001b.

. Portaria GM/MS nº 777, de 28 de abril de 2004. Dispõe sobre os procedimentos técnicos para a notificação compulsória de agravos à saúde do trabalhador em rede de serviços sentinela específica, no Sistema Único de Saúde - SUS. Diário Oficial [da] República Federativa do Brasil, Brasília, DF, 2004. Disponível em: <http://dtr2001.saude.gov.br/portal/ arquivos/pdf/Portaria777.pdf $>$. Acesso em 7 abr. 2011.

. Portaria no $1.068 / \mathrm{GM}$ de 4 de julho de 2005 . Dispõe sobre a ampliação e o fortalecimento 
da Rede Nacional de Atenção Integral à Saúde do Trabalhador - RENAST no Sistema Único de Saúde - SUS e dá outras providências. Diário Oficial [da] República Federativa do Brasil, Brasília, DF, 2005a. Disponível em: http://dtr2001.saude.gov.br/sas/ PORTARIAS/Port2005/GM/GM-1068.htm. Acesso em: 7 abr. 2011.

. Portaria GM/MS nº 2.437 , de 7

dezembro de 2005. Dispõe sobre a ampliação e o fortalecimento da Rede Nacional de Atenção Integral à Saúde do Trabalhador - Renast no Sistema Único de Saúde - SUS e dá outras providências. Diário Oficial [da] República Federativa do Brasil, Brasília, DF, 2005b. Disponível em: <http:/dtr2001.saude.gov.br/sas/ PORTARIA/Port2005/GM/GM-2437.htm > . Acesso em: 6 abr. 2011.

Rede Nacional de Atenção Integral

à Saúde do Trabalhador - manual de gestão e gerenciamento, 2006. Disponível em: < http://portal. saude.gov.br/portal/arquivos/pdf/ManualRenast07. pdf> Acesso em: 7 abr. 2011.

. Ministério da Saúde. Portaria GM nº 154, de 24 de janeiro de 2008. Cria os Núcleos de Apoio à Saúde da Família - NASF. Diário Oficial [da] República Federativa do Brasil, Brasília, DF, 2008. Disponível em: <http://www.saude.sp.gov.br/resources/ profissional/acesso_rapido/gtae/Saude_pessoa_idosa/ portaria_n_154_de_24_de_janeiro_de_2008_pdf $>$. Acesso em: 7 abr. 2011.

. Manual de gestão da vigilância em saúde. Brasília: Ministério da Saúde (Série A. Normas e manuais técnicos), 2009.

CAMPOS, G. W. S. O SUS entre a tradição dos sistemas nacionais e o modo liberal-privativo para organizar o cuidado à saúde. Ciência \& Saúde Coletiva, Rio de Janeiro, v. 12, p. 1865-1874, 2007. Suplemento.

CECCIM, R. B. Réplica. Interface, Botucatu, v. 9, n. 16, p. 175-177, fev. 2005.

CONSELHO FEDERAL DE PSICOLOGIA. A instituição sinistra - mortes violentas em hospitais psiquiátricos no Brasil. Brasília, 2001.

. Relatório de inspeção nacional de unidades psiquiátricas em prol dos direitos humanos. Brasília: CFP, 2004.

. Um retrato das unidades de internação de adolescentes em conflito com a lei. Relatório sobre as inspeções às unidades de internação de adolescentes em conflito com a lei. Brasília: CFP, 2006.

. Relatório de inspeção a Instituições de Longa Permanência para Idosos (ILPIs). Brasília: CFP, 2008a.

. Saúde do trabalhador no âmbito da saúde pública: referências para atuação do psicólogo. Brasília: CFP/CREPOP, 2008b.

. A prática da psicologia e o núcleo de apoio à saúde da família. Brasília: CFP, 2009.
CORDEIRO, R. et al. O sistema de vigilância de acidentes do trabalho de Piracicaba, São Paulo, Brasil. Cadernos de Saúde Pública, Rio de Janeiro, v. 21, n. 5, p. 1574-1583, 2005.

COSTA, D.; et al. Programa de saúde dos trabalhadores: a experiência da Zona Norte: uma alternativa em Saúde Pública. São Paulo: Hucitec, 1989.

FARINA, A. S.; NEVES, T. F. S. Formas de lidar com o desemprego: possibilidades e limites de um projeto de atuação em psicologia social do trabalho. Cadernos de Psicologia Social do Trabalho, São Paulo, v. 10, n. 1, p. 21-36, 2007.

FOUCAULT, M. História da loucura. São Paulo: Perspectiva, 1972.

GARBIN, A. C. Representações na mídia impressa sobre o assédio moral no trabalho. 2009. 169 f. Dissertação (Mestrado em Saúde Pública)-Faculdade de Saúde Pública, Universidade de São Paulo, São Paulo, 2009.

GARBIN, A. C.; KANASAWA, K. C.; URTADO, G. M. $O$ processo de implantação da Rede de Atenção Integral à Saúde do Trabalhador em um município da Grande São Paulo: relato de uma experiência. 2007. 24 f. Trabalho de Conclusão de Curso (Especialização em Saúde do Trabalhador)-Faculdade de Saúde Pública, Universidade de São Paulo, São Paulo, 2007.

JARDIM, S. R.; GLINA, D. M. R. O diagnóstico dos transtornos mentais relacionados ao trabalho. In: GLINA, D. M. R.; ROCHA, L. E. (Org.). Saúde mental no trabalho: desafios e soluções. São Paulo: VK, 2000.

LACAZ, F. A. C. Saúde do trabalhador: um estudo sobre as formações discursivas da Academia, dos Serviços e do Movimento Sindical. 1996. 435 f. Tese (Doutorado)- Faculdade de Ciências Médicas, Universidade Estadual de Campinas, Campinas, 1996.

LAURELL, A. C. Trabajo y salud: estado del conocimiento. In: FRANCO, S. et al. (Org.). Debates en medicina social. Quito: OPAS/ALAMES, 1991. p. 249339. (Serie Ddesarollo de recursos humanos, 92)

LIMA, M. E. A. Transtornos mentais e trabalho: o problema do nexo causal. Revista de Administração da FEAD-Minas, Belo Horizonte, v. 2, n. 1, p. 73-80, jun. 2005.

. A polêmica em torno do nexo causal entre distúrbio mental e trabalho. In: CONGRESSO INTERNACIONAL SOBRE SAÚDE MENTAL NO TRABALHO, 2., 2006, Goiânia. Anais... São Paulo: Cir Gráfica e Editora, 2007. p. 161-169,

MAENO, M.; CARMO, J. C. Saúde do trabalhador no SUS: aprender com o passado, trabalhar o presente, construir o futuro. São Paulo: Hucitec, 2005.

MERHY, E. E. et al. Em busca de ferramentas analisadoras das tecnologias em saúde: a informação e o dia a dia de um serviço, interrogando e gerindo trabalho em saúde. In: MERHY, E. E.; ONOCKO, R. (Orgs.). Praxis en salud un desafío para lo publico. São Paulo: Hucitec, 1997. p. 113-150. 
MINAYO-GÓMEZ, C.; THEDIM-COSTA, S. M. A construção do campo de saúde do trabalhador: percurso e dilemas. Cadernos de Saúde Pública, Rio de Janeiro, v. 13, supl. 2, p. 21-32, 1997.

ODDONE, I. et al. Ambiente de trabalho: a luta dos trabalhadores pela saúde. São Paulo: Hucitec, 1986.

OLIVEIRA, F. A Construção social dos discursos sobre o acidente de trabalho. 1997. 125 f. Dissertação (Mestrado em Psicologia)-Instituto de Psicologia, Universidade de São Paulo, São Paulo, 1997.

PASSOS, I. C. F. Criando redes de ensino, intervenção e pesquisa na saúde mental em sua interface com a saúde coletiva. Cadernos Brasileiros de Saúde Mental, v. 1, n. 1, jan-abr. 2009.

SÃO PAULO (Estado). Secretaria de Estado da Saúde. Resolução SS - 63, de 30 de abril de 2009. Regulamenta o fluxo de notificações de agravos à saúde do trabalhador, no âmbito do Estado de São Paulo. no 80 - Diário Oficial [do] Estado de São Paulo, 1 maio 2009, Seção 1, p. 25.

SATO, L. A representação social do trabalho penoso. In: SPINK, M. J. (Org.) O conhecimento no cotidiano: as representações sociais na perspectiva da psicologia social. São Paulo: Brasiliense, 1993.

SATO, L.; BERNARDO, M. H. Saúde mental e trabalho: os problemas que persistem. Ciência \& Saúde Coletiva, Rio de Janeiro, v. 10, n. 4, p. 869-878, 2005.

SATO, L.; LACAZ, F. A. C.; BERNARDO, M. H. Psicologia e saúde do trabalhador: as experiências com a emergência de um espaço de práticas e de investigação em Saúde Pública de São Paulo. Estudos de Psicologia, Natal, v. 11, p. 281-288, 2006.

SATO, L.; VALENTE, L. A.; FREITAS, N. B. B. Mapa de risco: origem e aplicação legal. Decisão, v. 14, p. 13-15, ago. 1993.
SCARCELLI, I. R. O movimento antimanicomial e a rede substitutiva em saúde mental: a experiência do município de São Paulo (1989-1992). 1998. 149 f. Dissertação (Mestrado em Psicologia Social)-Instituto de Psicologia, Universidade de São Paulo, São Paulo, 1998.

SCARCELLI, I. R.; ALENCAR, S. L. S. Saúde mental e saúde coletiva: intersetorialidade e participação em debate. Cadernos Brasileiros de Saúde Mental, São Paulo, v. 1, n. 1, jan-abr. 2009.

SCHILLING, R. S. F. More effective prevention in occupational health practice. Journal of the Society of Occupational Medicine, v. 39, n. 3, p. 71-79, 1984.

SILVA, R. G.; FISCHER, F. M. Incentivos governamentais para promoção da segurança e saúde no trabalho: em busca de alternativas e possibilidades. Saúde e Sociedade, São Paulo, v. 17, n. 4, p. 11-21, 2008.

TAMBELLINI, A . T. A política oficial de desenvolvimento científico e tecnológico no Brasil na área de saúde e trabalho: discurso e prática. In: ASSOCIAÇÃO BRASILEIRA DE PÓS-GRADUAÇÃO EM SAÚDE COLETIVA. Ensino da saúde pública, da medicina preventiva, e da medicina social no Brasil. Rio de Janeiro: Abrasco, 1984. p. 11-38.

TERRA, C. P.; et al. Desemprego: discurso e silenciamento: um estudo com clientes de um serviço de aconselhamento psicológico. Cadernos de Psicologia Social do Trabalho, São Paulo, v. 9, n. 1, p. 33-51, 2006.

VIEIRA, C. E. C. O nexo causal entre transtorno de estresse pós-traumático e trabalho: controvérsias acerca do laudo de uma perícia judicial. Revista Brasileira de Saúde Ocupacional, São Paulo, v. 34, n. 120, p. 150-162, 2009. 